\title{
Association between hypertension and deep vein thrombosis after orthopedic surgery: a meta-analysis
}

Lei Huang, Jie Li and Yong Jiang*

\begin{abstract}
Background: We aimed to analyze the association between hypertension and deep vein thrombosis (DVT) after orthopedic surgery.

Methods: Relevant studies were identified by a search of PubMed, Embase, China National Knowledge Infrastructure, Wanfang, the Chinese Biomedical Literature, and Weipu database until December 2015. The association between hypertension and DVT after orthopedic surgery was assessed by pooled odds ratios (ORs) and $95 \%$ confidence intervals $(\mathrm{Cls})$. Heterogeneity was evaluated by the Chi-square test based on $Q$ statistic and $P^{2}$ statistics. Finally, publication bias was evaluated by Egger's test.

Results: A total of 16 articles with 68,955 males and 53,057 females were eventually identified. Studies yielded effects for homogeneous $\left(Q=38.41, P=0.0008\right.$, and $\left.P^{2}=60.9 \%\right)$. Meta-analysis showed that hypertension was associated with DVT orthopedic surgery (OR 2.89, $95 \% \mathrm{Cl} 2.18-3.83, Z=7.38, P<0.05)$. No statistical evidence of publication bias was found among studies $(t=1.90, P=0.08)$. The funnel plot was symmetry, and the results were reliable.
\end{abstract}

Conclusions: Hypertension may promote DVT after orthopedic surgery, and may be an important risk factor of DVT occurrence.

Keywords: Meta-analysis, Hypertension, Deep vein thrombosis

\section{Background}

Hypertension is one of the major causes of disease burden all over the world [1]. In 2000, it was estimated that approximately 1 billion cases suffered hypertension and by 2025 , the number is predicted to increase to 1.56 billion [2]. It is one of the most important risk factors for heart disease, stroke, coronary artery disease, and premature death [3]. Obesity, smoking, alcohol consumption, age, and education have been reported to play important roles in the risk of untreated and uncontrolled hypertension [4-6].

Deep vein thrombosis (DVT) is a systemic disease with a incidence of 67 per 100,000 of cases every year [7]. DVT could lead to postphlebitic syndrome, pulmonary

*Correspondence: jiangyongshh@hotmail.com

Department of Orthopedics, The First Affiliated Hospital of Dalian Medical

University, No 5, Longbin road, Development Zone, Dalian 116600, China embolism, and even death. In spite of adequate treatment, $1-8 \%$ of patients developing pulmonary embolization will die $[8,9]$ and others will undergo long-term complications including chronic thromboembolic pulmonary hypertension and postphlebitic syndrome [10]. DVT is commonly associated with several co-morbidities. Over the past several years, studies on the association between DVT and hypertension have been reported, but the results are inconsistent. Some studies verified that hypertension could increase the development of DVT [11, 12]. However, Wang et al. [13] and Song et al. [14] reported that there was no statistically significant correlation between DVT and hypertension. Therefore, the controversial issue remains to be investigated.

Thus, in the current study, we performed a meta-analysis of available eligible studies to better elucidate the association between hypertension and DVT after orthopedic surgery. 


\section{Methods}

The paper did not involve any human or animal study, so the ethical approval was not required.

\section{Literature search}

We searched electronic databases PubMed (http://www. ncbi.nlm.nih.gov/pubmed), Embase (http://www.embase. com), China National Knowledge Infrastructure (CNKI, http://www.cnki.net/), Wanfang (http://g.wanfangdata. com.cn/), the Chinese BioMedical Literature (CBM, http://www.sinomed.ac.cn/), and Weipu database (http:// www.cqvip.com/) updated to December 2015 for all the publications on the association between hypertension and DVT. The search terms were hypertension or high blood pressure or HBP; deep vein thrombosis or thrombose veineuse profonde or DVT or deep venous thrombosis; orthopedic post-operation or orthopedic or orthopaedic and postoperative. Language restrictions were not used for the search.

\section{Study selection}

Studies were included if they met the following criteria: (1) the observation group was patients with DVT after orthopedic surgery and the control group was patients without DVT after orthopedic surgery; (2) published on association between hypertension (blood pressure $>140 / 90 \mathrm{~mm} \mathrm{Hg}$ ) and DVT after orthopedic surgery in Chinese or English; (3) the number of patients with hypertension in the observation group and control group could be obtained. Studies were excluded if they were reviews, reports, or letters.

\section{Data extraction}

With the standard protocol, two investigators independently extracted the following data from the included studies: the first author, publication year, study time and region, the number of patients in control group or observation group, the number of patients with hypertension, and the demographic characteristics (sex, age, hyperlipidemia, and diabetes mellitus). Disagreements were resolved through discussion or settled by a third reviewer.

\section{Statistical analysis}

Meta-analysis was carried out using R 3.12 software. The odds ratio (OR) and its $95 \%$ confidence interval (CI) were calculated for effect index. Heterogeneity test was evaluated by Chi-square based on $Q$ statistic [15] and $I^{2}$ statistics [16]. A random effects model was used to combine the data for the heterogeneous outcomes $(P<0.05$ or $I^{2} \geq 50 \%$; otherwise, a fixed effects model was used
[17]. A sensitivity analysis was performed, in which one study was removed at a time and others were analyzed to examine the influence of a single study on the combined OR value [18]. Publication bias was evaluated through funnel plot visual analysis with the Egger's tests [19, 20]. A $P$ value less than 0.05 was considered statistically significant.

\section{Results}

\section{Characteristics of included studies}

The process of study selection was shown in Fig. 1. Initially, a total of 124 potentially relevant articles were retrieved from the databases (PubMed 18; Embase 11; CNKI 8; Wanfang 80; Weipu 2; CBM 5). Then, 108 articles were left after eliminating the duplicate publication, and 77 of them were excluded after screening the title and abstract. As a consequence, 31 articles were left and 15 (3 review, 1 letter, 3 case-report, 2 repeated people, and 6 did not provide sufficient data) of them were excluded after screening the full text. Finally, 16 articles [11, 12, 21-34] including 68,955 males and 53,057 females were included in this meta-analysis (Table 1). These studies were published between 2009 and 2015 with researches done between 2005 and 2014.

\section{Merging quantitative data}

The homogeneity analysis exhibited good with heterogeneity test $\left(Q=38.41, P=0.0008\right.$, and $\left.I^{2}=60.9 \%\right)$. Then, the random effects model was used for further analysis. Meta-analysis showed that hypertension was associated with DVT after orthopedic surgery (OR 2.89, $95 \%$ CI 2.18-3.83, Z 7.38, $P<0.05$, Fig. 2). Sensitivity analysis showed that our results were stable (OR 2.89, $95 \% \mathrm{CI}$ : 2.18-3.83, Fig. 3). After Egger's regression test, no publication bias among studies was found $(\mathrm{t}=1.90, P=0.08)$. The funnel plot was symmetry, so there was no publication bias and the result was reliable (Fig. 4).

\section{Subgroup analysis}

Subgroup analysis pointed out that heterogeneity was decreased to different degrees (Table 2). In addition, the results of meta-analysis in each subgroup showed that hypertension may promote the formation of DVT after orthopedic surgery.

\section{Discussion}

This is the first systematic review and meta-analysis of studies, to our knowledge, examining the correlation between hypertension and DVT after orthopedic surgery. Totally 16 articles with 68,955 males and 53,057 females 


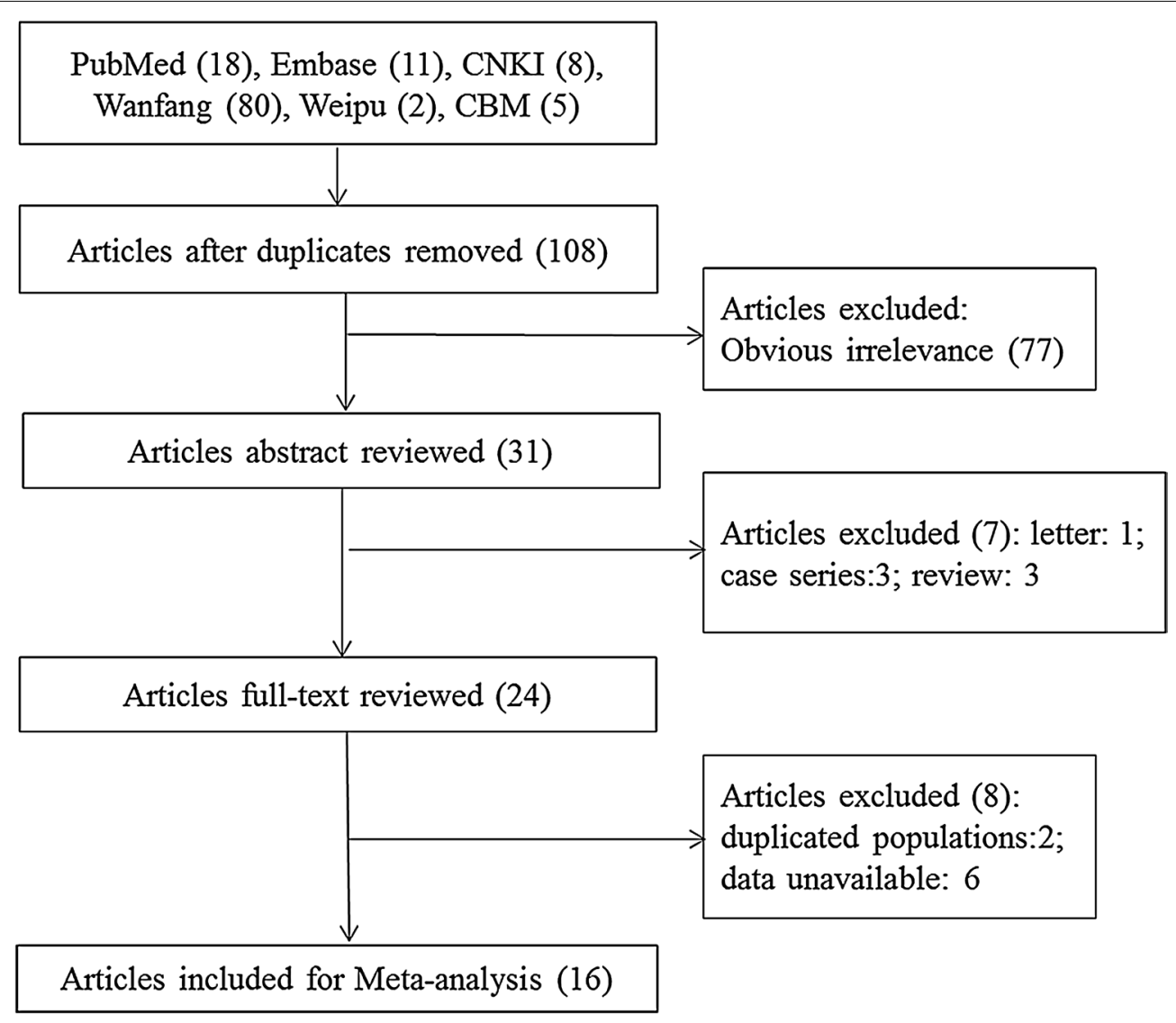

Fig. 1 Flow diagram of study selection

were included in this meta-analysis. The results showed that hypertension might promote DVT after orthopedic surgery (OR 2.89, $95 \% \mathrm{CI} 2.18-3.83, Z=7.38$ ).

In spite of the inherent risk of developing DVT for patients with orthopedic surgery, researches on risks of developing DVT were limited. Red blood cell storage has been found to be associated with increased incidence of DVT [35]. A previous report has indicated that patients with increased concentrations of factor VIII and von Willebrand's factor have increased risk of DVT [36]. Compared with healthy controls, levels of red cell distribution width were higher in pre-hypertensive and hypertensive patients independently of age, inflammatory status, and anemia, suggesting the correlations between red cell distribution width and hypertension [37]. All of these may hint a potential relationship between DVT and hypertension.

The only risk factor of DVT in accordance with the conclusion from this meta-analysis is hypertension, which has already been verified previously. Several prospective studies have addressed the associations between hypertension and DVT. Patients with hypertension have been found with 2-fold increased likelihood of developing DVT [38]. In the current study, the results of metaanalysis in each subgroup have showed that hypertension may promote the formation of DVT after orthopedic surgery. In addition, hypertension has been found as an independent predictor of venous thromboembolism (VTE) in the general population [39]. In another study, after a prospective registry of 5451 patients with DVT, Goldhaber et al. [40] have found that $50 \%$ patients have co-morbidities with hypertension. Kaisorn et al. [41] have also reported that hypertension may independently increase the risk of developing operative DVT (OR 1.785; $95 \%$ CI 1.180-2.699; $P=0.006$ ).

Age is a high prevalence of asymptomatic DVT event which has been identified in patients over 80 years [42]. A previous study with 102 consecutive patients of follow-up 
Table 1 Characteristics of included studies in the meta-analysis

\begin{tabular}{|c|c|c|c|c|c|c|c|c|c|c|}
\hline Author & Public year & Study year & $\begin{array}{l}\text { Study } \\
\text { location }\end{array}$ & DVT & No. & Sex (M/F) & Age & $\begin{array}{l}\text { Hyperlipi- } \\
\text { demia }\end{array}$ & $\begin{array}{l}\text { Diabetes } \\
\text { mellitus }\end{array}$ & Hypertension \\
\hline \multirow[t]{2}{*}{ Ma Jun } & \multirow[t]{2}{*}{2009} & \multirow{2}{*}{$\begin{array}{r}2007.2- \\
2007.7\end{array}$} & \multirow[t]{2}{*}{ Sichuan } & Yes & 17 & $4 / 13$ & $15(\geq 65)$ & $15^{\mathrm{a}}$ & 4 & 6 \\
\hline & & & & No & 34 & $9 / 25$ & $16(\geq 65)$ & $7^{\mathrm{a}}$ & 5 & 5 \\
\hline \multirow[t]{2}{*}{ Zhang Ke-yun } & \multirow[t]{2}{*}{2014} & \multirow{2}{*}{$\begin{array}{r}2010.2- \\
2012.1\end{array}$} & \multirow[t]{2}{*}{ Hunan } & Yes & 28 & $6 / 22$ & $28(\geq 65)$ & $24^{\mathrm{a}}$ & 6 & 8 \\
\hline & & & & No & 64 & $17 / 47$ & $30(\geq 65)$ & $17^{\mathrm{a}}$ & 10 & 12 \\
\hline \multirow[t]{2}{*}{ Wu Fang-li } & \multirow[t]{2}{*}{2011} & \multirow{2}{*}{$\begin{array}{l}2008.5- \\
2009.12\end{array}$} & \multirow[t]{2}{*}{ Zhejiang } & Yes & 15 & $6 / 9$ & $70.08 \pm 12.18$ & NA & NA & 9 \\
\hline & & & & No & 171 & $36 / 135$ & $63.83 \pm 10.6$ & NA & NA & 36 \\
\hline \multirow{2}{*}{$\begin{array}{l}\text { Zheng Gui- } \\
\text { juan }\end{array}$} & \multirow[t]{2}{*}{2015} & \multirow{2}{*}{$\begin{array}{r}2013.1- \\
2014.6\end{array}$} & \multirow[t]{2}{*}{ Beijing } & Yes & 16 & $3 / 13$ & $14(\geq 65)$ & $14^{\mathrm{a}}$ & 6 & 5 \\
\hline & & & & No & 36 & $12 / 24$ & $16(\geq 65)$ & $9^{\mathrm{a}}$ & 4 & 7 \\
\hline \multirow[t]{2}{*}{ He Han-liang } & \multirow[t]{2}{*}{2014} & \multirow{2}{*}{$\begin{array}{l}2011.1- \\
2013.12\end{array}$} & \multirow[t]{2}{*}{ Zhejiang } & Yes & 203 & $134 / 69$ & $57(>60)$ & 73 & NA & 115 \\
\hline & & & & No & 3967 & 2399/1771 & $833(>60)$ & 1019 & NA & 1940 \\
\hline \multirow[t]{2}{*}{ Yao Jie } & \multirow[t]{2}{*}{2013} & \multirow[t]{2}{*}{ NA } & \multirow[t]{2}{*}{ Ningxia } & Yes & 212 & $145 / 67$ & $76(>64)$ & $113^{\mathrm{a}}$ & 20 & 43 \\
\hline & & & & No & 4921 & $3012 / 1909$ & $854(>64)$ & $1113^{\mathrm{a}}$ & 152 & 286 \\
\hline \multirow[t]{2}{*}{ Rong Jin-yang } & \multirow[t]{2}{*}{2013} & \multirow{2}{*}{$\begin{array}{r}2009.1- \\
2013.4\end{array}$} & Shanxi & Yes & 130 & $76 / 54$ & $48(28-70)$ & 30 & 33 & 48 \\
\hline & & & & No & 134 & $78 / 56$ & $50(30-72)$ & 9 & 10 & 13 \\
\hline Long Jiang & 2013 & $2009.5-$ & Yunnan & Yes & 73 & NA & $49.3 \pm 26.1$ & 47 & 53 & 49 \\
\hline & & 2012.5 & & No & 72 & NA & & 23 & 37 & 25 \\
\hline Ya Jun & 2014 & $2010.3-$ & Yunnan & Yes & 25 & $34 / 16$ & $62.5 \pm 1.2$ & NA & 8 & 9 \\
\hline & & 2013.3 & & No & 25 & & & NA & 6 & 4 \\
\hline Sun Yong-fei & 2011 & $2005.5-$ & Zhejiang & Yes & 70 & $30 / 40$ & $45.5 \pm 7.1$ & NA & 18 & 20 \\
\hline & & & & No & 70 & $30 / 40$ & $45.6 \pm 7.2$ & NA & 8 & 9 \\
\hline Wang Da-wei & 2012 & 2007.4- & Liaoning & Yes & 91 & $101 / 64$ & $38.2 \pm 8.23$ & 29 & 19 & 23 \\
\hline & & & & No & 74 & & & 6 & 6 & 8 \\
\hline Wang Xiao- & 2013 & 2011.10- & Guangdong & Yes & 52 & $64 / 39$ & $59.8 \pm 4.3$ & 36 & 34 & 31 \\
\hline & & 2012.11 & & No & 51 & & $39.4 \pm 3.9$ & 15 & 19 & 14 \\
\hline Huang Kun & 2014 & 2010-2013 & Jiangsu & Yes & 80 & $57 / 23$ & $51.3 \pm 11.4$ & 26 & 23 & 26 \\
\hline & & & & No & 80 & $55 / 25$ & $50.8 \pm 10.2$ & 9 & 14 & 12 \\
\hline Guo Chang- & 2013 & $2011.1-$ & Zhejiang & Yes & 98 & $113 / 67$ & $37.5 \pm 1.2$ & 22 & 28 & 22 \\
\hline & & 2013.1 & & No & 82 & & & 9 & 10 & 8 \\
\hline Yang Si-dong & 2015 & 2013.7- & Hebei & Yes & 147 & $410 / 451$ & $54(15-87)$ & NA & 18 & 54 \\
\hline & & & & No & 714 & & & NA & 66 & 161 \\
\hline Zheng Sui- & 2013 & $2011.10-$ & Zhejiang & Yes & 58 & $30 / 28$ & $68.7 \pm 17.1$ & NA & 36 & 25 \\
\hline & & 0 & & No & 62 & $32 / 30$ & $55.6 \pm 11.2$ & NA & 8 & 10 \\
\hline
\end{tabular}

a Triglyceride $\geq 1.7 \mathrm{mmol} / \mathrm{L}, M$ male, $F$ female, $D V T$ deep vein thrombosis, $N A$ not available

found that age greater than 65 years, body mass index $(\mathrm{BMI})>30 \mathrm{~kg} / \mathrm{m}^{2}$, and smoking were risk factors for DVT [43]. In a recent study comprising 87574 individuals found that obesity was a causal risk factor for DVT [44]. Examining on VTE, Chamberlain et al. [45] found that low-density lipoprotein cholesterol was not an risk factor of VTE. Another study with 855 men (65 VTE events) identified that smoking and waist circumference were risk factors for VTE, whereas high cholesterol and hypertension were not [46]. In addition, a Copenhagen City Heart Study pointed out that hypertension, smoking, and obesity were important risk factors for VTE, whereas total/ high-density lipoprotein/low-density lipoprotein cholesterol, triglyceride, and diabetes mellitus were not [47].
Some limitations of this study should be addressed. First, only published studies were included and publication bias might exist, although no significant bias was detected by Egger's test. Second, significant heterogeneity across studies was presented in overall and subgroup analysis, which might influence the pooled results. Third, although there was no limitation for language, only Chinese population was included, which might lead to bias. Fourth, as limited researches included in this meta-analysis, association between DVT and age, BMI, or gender was not analyzed. Finally, the small sample size was still insufficient to obtain a conclusive result. However, larger and well-designed studies based on different populations are warranted to validate our results. 


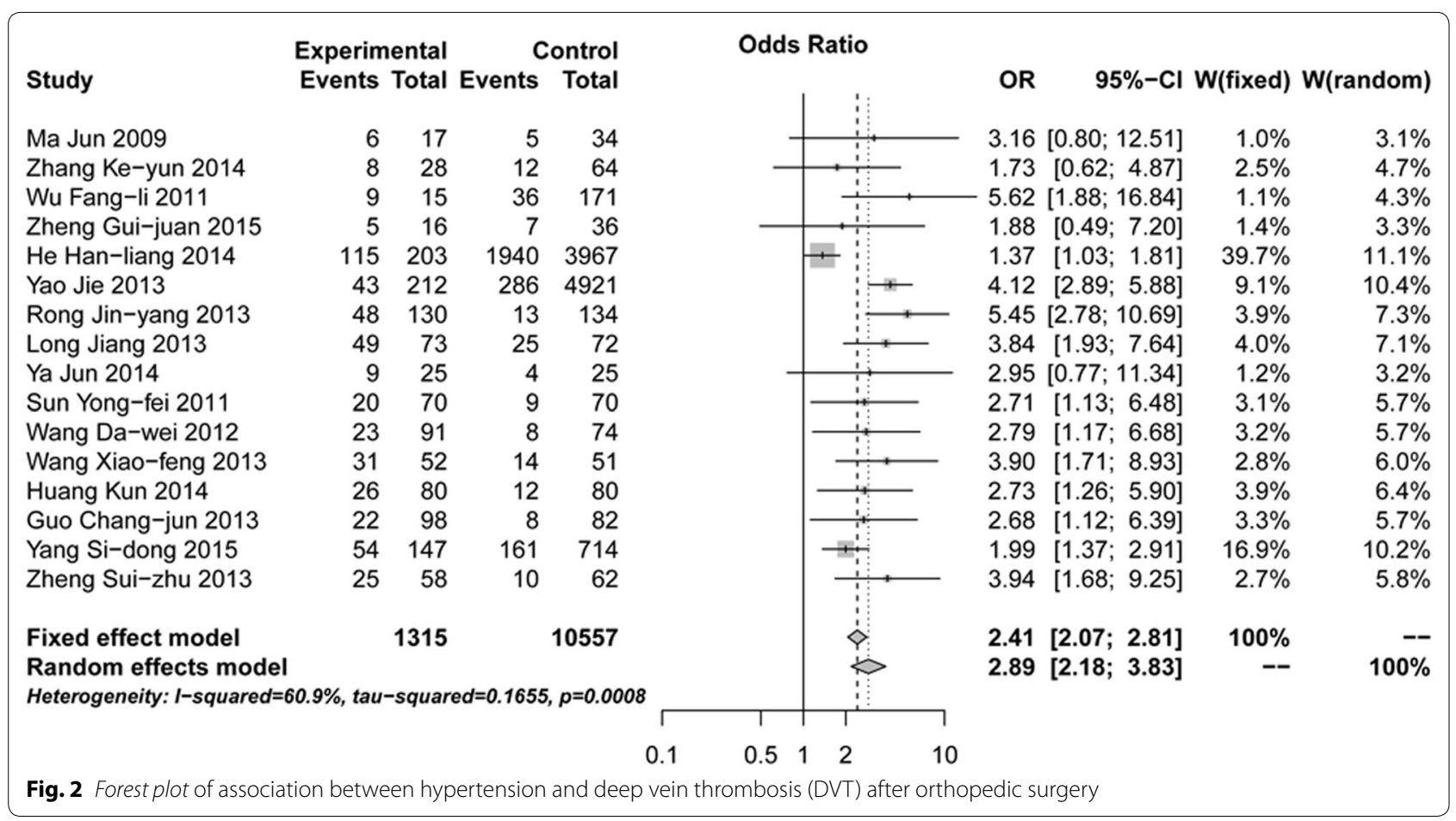

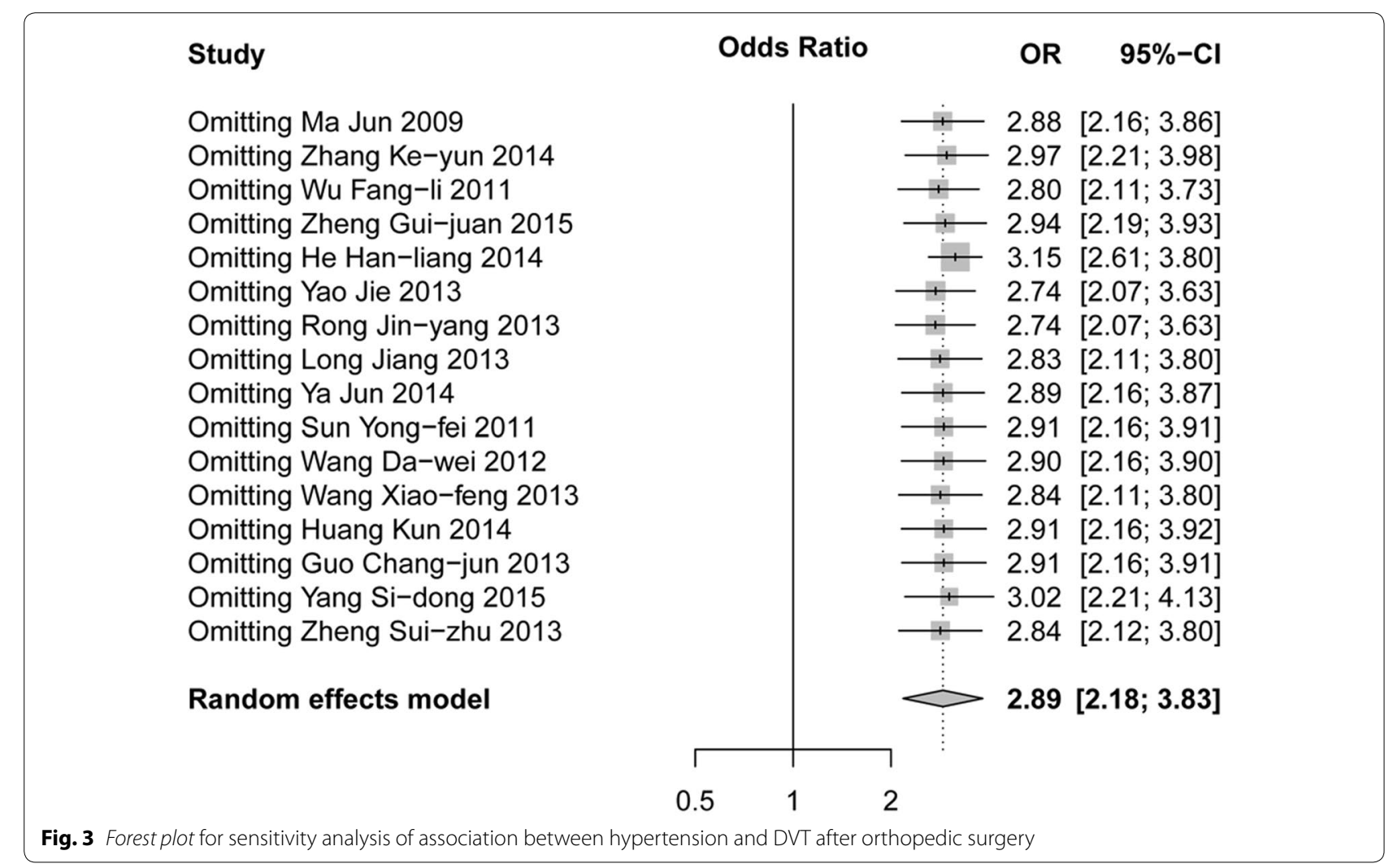




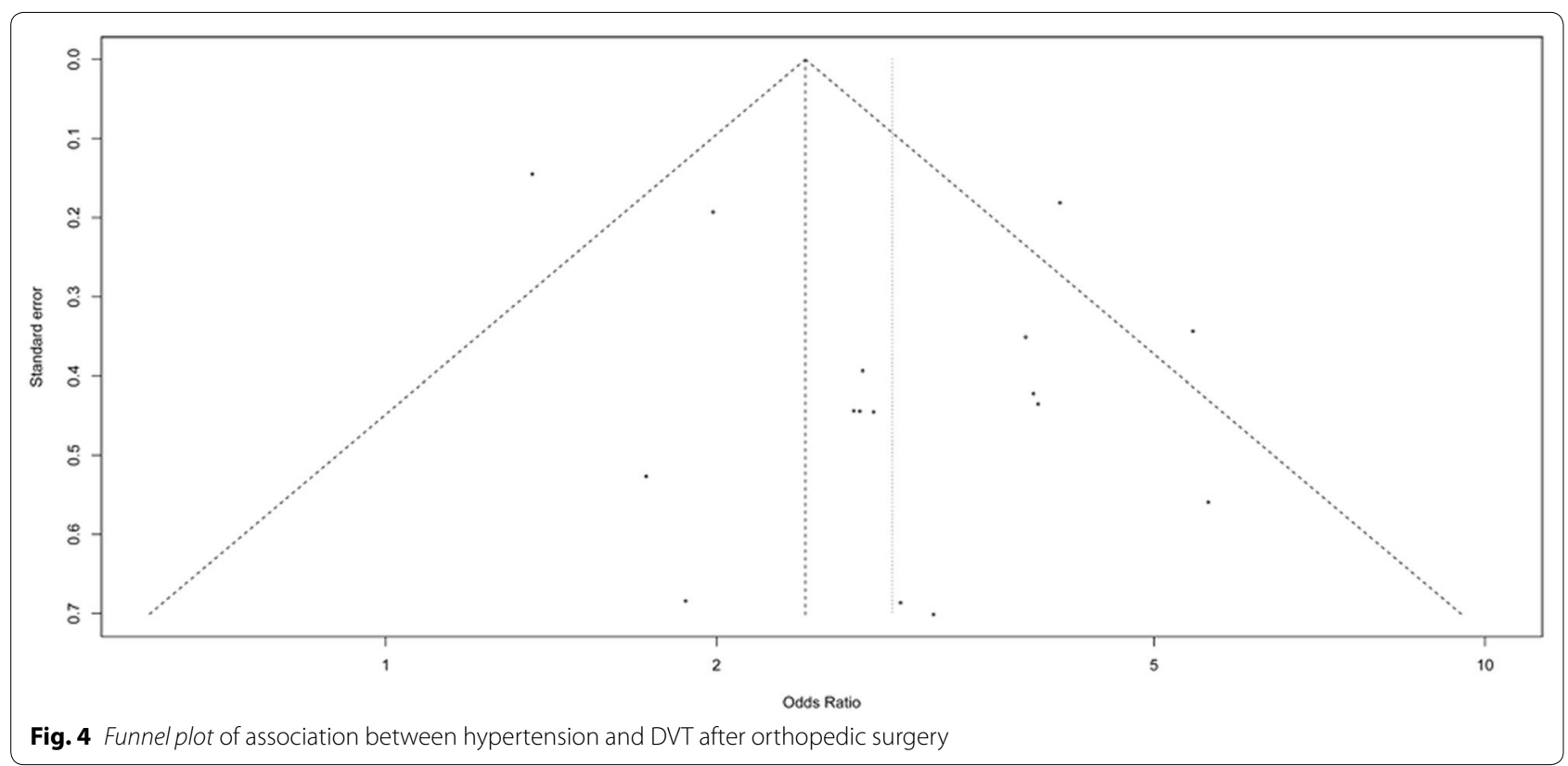

Table 2 Subgroup analyses of associations between hypertension and deep vein thrombosis after orthopedics surgery

\begin{tabular}{llcccrr}
\hline Classification & Item & $\boldsymbol{N}$ & $\boldsymbol{I}^{\mathbf{2}}$ (\%) & $\boldsymbol{P}$ & Model & OR [95 \% Cl] \\
\hline Regional distribution & Western China & 4 & 0 & 0.9498 & $F$ & $3.89[2.85-5.30]$ \\
& Central China & 3 & 71.5 & 0.0298 & $R$ & $2.70[1.32-5.52]$ \\
& Eastern China & 9 & 53.9 & 0.0268 & $R$ & $3.95[2.92-5.33]$ \\
The proportion of including & $N<500$ & 13 & 0 & 0.8881 & $F$ & $3.37[2.63-4.31]$ \\
& $N \geq 500$ & 3 & 91.5 & $<0.0001$ & $R$ & $2.23[1.14-4.34]$ \\
\hline
\end{tabular}

OR odds ratio, $R$ random effects model, $F$ fixed effect model

In conclusion, this study showed that hypertension might promote DVT after orthopedic surgery, and it might be an important risk factor of DVT occurrence.

\section{Authors' contributions}

LH participated in the design of this study and performed the statistical analysis. JL carried out the study and collected important background information. YJ drafted the manuscript. All authors read and approved the final manuscript.

\section{Acknowledgements}

None.

\section{Competing interests}

The authors declare that they have no competing interests.

Received: 14 January 2016 Accepted: 12 March 2016

Published online: 22 March 2016

\section{References}

1. Lopez AD, Mathers CD, Ezzati M, Jamison DT, Murray CJ. Global and regional burden of disease and risk factors, 2001: systematic analysis of population health data. Lancet. 2006;367(9524):1747-57.
2. Kearney PM, Whelton M, Reynolds K, Muntner P, Whelton PK, He J. Global burden of hypertension: analysis of worldwide data. Lancet. 2005;365(9455):217-23.

3. Organization WH. World health statistics 2012 [internet]. Genebra: WHO; 2012.

4. Danon-Hersch N, Marques-Vidal P, Bovet P, Chiolero A, Paccaud F, Pecoud A, Hayoz D, Mooser V, Waeber G, Vollenweider P. Prevalence, awareness, treatment and control of high blood pressure in a Swiss city general population: the CoLaus study. Eur J CardioL Prev Rehabil. 2009;16(1):66-72.

5. Tian S, Dong G-H, Wang D, Liu M-M, Lin Q, Meng X-J, Xu L-X, Hou H, Ren Y-F. Factors associated with prevalence, awareness, treatment and control of hypertension in urban adults from 33 communities in China: the CHPSNE study. Hypertens Res. 2011;34(10):1087-92.

6. Agyemang C, Van Valkengoed I, Koopmans R, Stronks K. Factors associated with hypertension awareness, treatment and control among ethnic groups in Amsterdam, the Netherlands: the SUNSET study. J Hum Hypertens. 2006;20(11):874-81.

7. White RH. The epidemiology of venous thromboembolism. Circulation. 2003;107(23):14-8.

8. Prandoni P, Lensing AW, Prins MR. Long-term outcomes after deep venous thrombosis of the lower extremities. Vasc Med. 1998;3(1):57-60.

9. Hirsh J, Bates SM. Prognosis in acute pulmonary embolism. Lancet. 1999:353(9162):1375-6.

10. Kahn SR, Ginsberg JS. Relationship between deep venous thrombosis and the postthrombotic syndrome. Arch Intern Med. 2004;164(1):17-26.

11. Chang-jun G. Risk factors of deep venous thrombosis after traumatic fracture. J N Pharm. 2013;8:99-100. 
12. Han-liang $\mathrm{H}$. Risk factors of deep venous thrombosis after orthopaedic surgery. Chin J Surg Integr Tradit West Med. 2014;6:593-5.

13. Wang C-J, Wang J-W, Chen L-M, Chen H-S, Yang B-Y, Cheng S-M. Deep vein thrombosis after total knee arthroplasty. J Formos Med Assoc. 2000;99(11):848-53.

14. Song EK, Kim JK, Lee KB, Seon JK. Deep vein thrombosis after total knee replacement: incidence and correlation with clinical risk factors. J Korean Knee Soc. 1998;10(1):18-22.

15. Lau J, loannidis JP, Schmid CH. Quantitative synthesis in systematic reviews. Ann Intern Med. 1997;127(9):820-6.

16. Higgins JP, Thompson SG, Deeks JJ, Altman DG. Measuring inconsistency in meta-analyses. Br Med J. 2003;327(7414):557.

17. Feng R-N, Zhao C, Sun C-H, Li Y. Meta-analysis of TNF 308 G/A polymorphism and type 2 diabetes mellitus. PLoS One. 2011;6(4):e18480.

18. Liu ZH, Ding YL, Xiu LC, Pan HY, Liang Y, Zhong SQ, Liu WW, Rao SQ, Kong DL. A meta-analysis of the association between TNF-alpha -308G > A polymorphism and type 2 diabetes mellitus in Han Chinese population. PLoS One. 2013;8(3):e59421. doi:10.1371/journal.pone.0059421.

19. Sterne JA, Egger M. Funnel plots for detecting bias in meta-analysis: guidelines on choice of axis. J Clin Epidemiol. 2001;54(10):1046-55.

20. Egger M, Smith GD, Schneider M, Minder C. Bias in meta-analysis detected by a simple, graphical test. BMJ. 1997;315(7109):629-34.

21. Da-wei W. Risk factors analysis of deep vein thrombosis in orthopaedic trauma patients. Seek Med Ask Med. 2012;10(4):10.

22. Fang-li W, Yan-feng M. Assessment of risk factors for deep vein thrombosis after total joint arthroplasty. J Med Res. 2011;40(5):109-11.

23. Gui-juan Z, Jia G. The influence factors of lower extremities deep venous thrombosis after hip replacement. Chin J Prim Med Pharm. 2015;22(13):1959-63.

24. Jiang L. Occurrence and risk factors of deep venous thrombosis after traumatic fracture. Seek Med Ask Med. 2013;11:03.

25. Jie $Y$, Jin-hai $M$, Wen-juan W, et al. Risk factors for deep vein thrombosis in lower extremity after orthopedic surgery. Chin J Anesthesiol. 2013;33(4):413-6.

26. Jin-yang R. Risk factors analysis of deep vein thrombosis after orthopaedic trauma. Med Forum. 2013;29:3873-4.

27. Jun M, Bin S, Jing Y, et al. Risk factors for deep vein thrombosis after total hip arthroplasty. Orthop J Chin. 2009;17(13):965-9.

28. Jun $Y$, Zhi-jian $M$, Peng $L$, et al. Factors analysis and clinical treatment of the patients after surgery with deep venous thrombosis. Chin Med Herald. 2014;11(10):25-7.

29. Ke-yun Z, Li-ming Y, Xu-hua Z, et al. Analyze the relationship between hip replacement and deep vein thrombosis. Guide Chin Med. 2014;14:34-5.

30. Kun H. Risk factors of deep venous thrombosis after orthopaedic trauma of 80 cases. All For Health. 2014;8(6):128-9.

31. Xiao-feng W. Risk factors of deep venous thrombosis after orthopaedic trauma of 103 cases. Guide Chin Med. 2013;30:429-30.

32. Yang SD, Liu H, Sun YP, Yang DL, Shen Y, Feng SQ, Zhao FD, Ding WY Prevalence and risk factors of deep vein thrombosis in patients after spine surgery: a retrospective case-cohort study. Sci Rep. 2015;5:11834. doi:10.1038/srep11834.
33. Yong-fei S, Zhi-hong L. Research analysis of risk factors analysis of deep vein thrombosis in orthopaedic trauma patients. Chin Modern Doct. 2011:49(18):255-6.

34. Sui-zhu Z, Yiing-ying W, Qian-qian J. Related risk factors analysis and nursing strategy of deep venous thrombosis after orthopaedic surgery. Chin J Gen Prac. 2013;11(11):1806-7.

35. Spinella PC, Carroll CL, Staff I, Gross R, Quay JM, Keibel L, Wade CE, Holcomb JB. Duration of red blood cell storage is associated with increased incidence of deep vein thrombosis and in hospital mortality in patients with traumatic injuries. Crit Care. 2009;13(5):R151.

36. Tirado I, Mateo J, Soria JM, Oliver A, Martínez-Sánchez E, Vallvé C, Borrell M, Urrutia T, Fontcuberta J. The ABO blood group genotype and factor VIII levels as independent risk factors for venous thromboembolism. Thromb Haemost. 2005;93(3):468-74.

37. Tanindi A, Topal FE, Topal F, Celik B. Red cell distribution width in patients with prehypertension and hypertension. Blood Press. 2012;21(3):177-81.

38. Semrad TJ, O'Donnell R, Wun T, Chew H, Harvey D, Zhou H, White RH. Epidemiology of venous thromboembolism in 9489 patients with malignant glioma. J Neurosurg. 2007;106(4):601-8.

39. Goldhaber SZ. Risk factors for venous thromboembolism. Am J Cardiol. 2010;56(1):1-7.

40. Goldhaber SZ, Tapson VF, Committee DFS. A prospective registry of 5,451 patients with ultrasound-confirmed deep vein thrombosis. Am J Cardiol. 2004;93(2):259-62.

41. Chaichana KL, Pendleton C, Jackson C, Martinez-Gutierrez JC, DiazStransky A, Aguayo J, Olivi A, Weingart J, Gallia G, Lim M. Deep venous thrombosis and pulmonary embolisms in adult patients undergoing craniotomy for brain tumors. Neurol Res. 2013;35(2):206-11.

42. Oger E, Bressollette L, Nonent M, Lacut K, Guias B, Couturaud F, Leroyer C, Mottier D. High prevalence of asymptomatic deep vein thrombosis on admission in a medical unit among elderly patients. Thromb Haemost. 2002;88(4):592-7.

43. Delis K, Hunt N, Strachan R, Nicolaides A. Incidence, natural history and risk factors of deep vein thrombosis in elective knee arthroscopy. Thromb Haemost. 2001;86(3):817-21.

44. Klovaite J, Benn M, Nordestgaard B. Obesity as a causal risk factor for deep venous thrombosis: a Mendelian randomization study. J Intern Med. 2015;277(5):573-84

45. Chamberlain AM, Folsom AR, Heckbert SR, Rosamond WD, Cushman M. High-density lipoprotein cholesterol and venous thromboembolism in the longitudinal Investigation of thromboembolism etiology (LITE). Blood. 2008;112(7):2675-80.

46. Hansson P-O, Eriksson H, Welin L, Svärdsudd K, Wilhelmsen L. Smoking and abdominal obesity: risk factors for venous thromboembolism among middle-aged men: the study of men born in 1913. Arch Intern Med. 1999;159(16):1886-90.

47. Holst AG, Jensen G, Prescott E. Risk factors for venous thromboembolism results from the Copenhagen City Heart Study. Circulation. 2010;121(17):1896-903.

\section{Submit your next manuscript to BioMed Central and we will help you at every step:}

- We accept pre-submission inquiries

- Our selector tool helps you to find the most relevant journal

- We provide round the clock customer support

- Convenient online submission

- Thorough peer review

- Inclusion in PubMed and all major indexing services

- Maximum visibility for your research

Submit your manuscript at www.biomedcentral.com/submit
() Biomed Central 